\title{
The union of conjunction and disjunction: The case of and/or
}

\author{
Brent Woo*
}

\begin{abstract}
And/or is a coordinator in English that has virtually never been remarked on in the syntactic literature on coordination. I present a new empirical survey of and/or, supported by naturally-occurring examples from several English corpora. I examine the basic distribution of and/or, and its interaction with collective predicates, relational modifiers with an internal reading, anaphors, 'respectively', semantic contradiction, quantifiers, and gapping with negation. Based on the distribution across corpora and its syntactic behavior, I argue that and/or is a completely lexicalized coordinator in productive use, and conclude that the constraints on the syntactic distribution of and/or are a union of the set of constraints on and and or.
\end{abstract}

Keywords. coordination; conjunction; disjunction; English

1. Introduction. The syntactic literature on coordination in English typically discusses a select few coordinating conjunctions in detail: and, but, and or (e.g., Munn 1993, Zoerner 1995). Recent research has proposed the class of coordinators is larger than previously thought. Newlyidentified English coordinators include focus-sensitive coordinators let alone and much less (Hulsey 2008), the intersective coordinator slash (Woo, to appear), and this paper proposes another: and/or. AND/OR is a complex coordinator that shows properties of both and and or. It is well-attested in many formal domains, including law, medicine, and linguistics, as shown in the examples in (1):

(1) a. Video and/or sound recordings obtained by police personnel [...] shall be made avail able for hearing and/or viewing by defense counsel. ${ }^{1}$

b. Brachydactyly and/or clinodactyly was a consistent feature in the hands and/or feet.

c. researchers who have defined grammaticality and/or acceptability in other ways might make a principled distinction between two types of judgment ${ }^{2}$

d. It is standard to find that object extraction is more liberal than subject and/or adjunct extraction $^{3}$

It is also found in informal domains, including entertainment, spontaneous speech, and other casual contexts, as shown in (2).

(2) a. So, who wants to touch and/or be touched by a famous person? ${ }^{4}$

b. Theres nowhere I wont go. As long as its horribly, horribly true and/or wrong. ${ }^{5}$

\footnotetext{
* I thank Barbara Citko, Kirby Conrod, Taylor Carrasco, members of the UW Syntax Roundtable, Zac Smith, and commenters at LSA 2017 for their suggestions and comments during preparation. This material was presented at the UW Syntax Roundtable and at the LSA Annual Meeting 2017. Author: Brent Woo, University of Washington (bwoo@uw.edu).

${ }^{1}$ Washington State Code; RCW 9.73.090b

2 Schütze 1996:26

${ }^{3}$ Phillips 2013:94

${ }^{4}$ Bob's Burgers, Season 2, Episode 9
} 
c. Give your figures and tables titles and/or captions. You can also use indentation, bold or italic font, outlining or borders, symbols, and/or bullets to highlight important information. ${ }^{6}$

And/or is a unique, lexicalized combination of and and or, combined by an orthographic slash $</>$. It is an established coordinator in English that shows systematic, regular, robust, and intentional use. The many published and televised instances of and/or, as well as corpus instances, are seldom followed by self-correction. This suggests it is not a production error. As shown above, and/or is not stylistically limited, and is attested in many contexts that cross-cut formal, informal, published, and spontaneous domains. And/or is fully lexicalized and integrated into the grammar, and is not ad-hoc compounding by orthographic slash $</>$. There are two observations that support this: other functional categories do not readily combine by orthographic slash:

*a/the, *that/if, *over/under. There are also virtually no instances of other binary combinations of coordinators: *and/but, *or/and, *but/and, *but/or, *or/but, and so on. The vanishingly rare exceptions seem to be either special literary devices or idiosyncratic to an author.

(5) The challenge must be seen not as "either/or" but as "and/and."7

$$
\text { ...when using encoding or/and decoding variables to predict ending performance }{ }^{8}
$$

Speakers consider variants like or/and anomalous. Google searches reveal and/or is found in a random sample of several other languages, as in Table 1. In these languages, the only combination found is the exact translated equivalent of and/or, apparently excluding any alternatives like or/and, as in English.

\begin{tabular}{ll}
\hline Language & and/or \\
\hline English & and/or \\
Czech & a/nebo \\
French & et/ou \\
Spanish & y/o \\
Italian & e/o \\
Russian & $i / i l i$ \\
Finnish & ja/tai \\
Serbo-Croatian & $i / i l i$ \\
Hebrew & v/o \\
\hline
\end{tabular}

Table 1: Attested versions of and/or in multiple languages.

This paper advocates for the inclusion of and/or in the standard repertoire of English coordinators. In Section 2, I present a brief discussion of its meaning. In Section 3, I present the results of a corpus study, showing attested examples of and/or in use. In Section 4, I show its syntactic behavior by comparing it to other coordinators in environments known to interact with coordination like negation and gapping, in order to demonstrate the main observation of this paper: the set

${ }^{5}$ Louis CK

${ }^{6}$ LSA Poster guidelines: 6 total instances of and/or: https://www.linguisticsociety.org/resource/lsa-poster-guidelines

7 AfricaArts journal; only found here.

${ }^{8}$ Weiser 2012. 
of constraints on and/or is the union of the set of constraints on conjunction and and disjunction or.

2. Meaning. And/or is, simply put, the semantic combination of and and or. There is an additional pragmatic component of speaker uncertainty: a speaker who uses and/or is either unsure or intentionally underspecifies which of the conjoined alternatives is the appropriate one. This speaker uncertainty component is derived as an implicature from the speaker's decision not to use a more "specific coordinator" (Gricean Maxim of Quality). A more "specific coordinator" is either and or or, both of which have narrower, more specific meanings. Consider these utterances.
a. John worked with Adam and Brice.
b. John worked with Adam or Brice.
c. John worked with Adam and/or Brice.

For each of the utterances in (3), the following interpretations are available. (3a) with and is best interpreted as (4a). (3b) is best interpreted as (4b).

(4) a. John worked with both Adam and Brice. (...definitely the 2 of them)

b. John worked with either Adam or Brice. (...definitely just 1 person)

c. John worked with Adam and/or Brice.

(... and I don't even know whether it was 1 or 2 people.)

The most felicitous interpretation of (3c) with and/or is (4c), where the speaker is totally uncertain which combination of people John worked with, and whether it was 1 or 2 people that John worked with. The use of and/or conveys this extra component of speaker uncertainty.

3. Distribution. The regular use of and/or is supported by its substantial presence across several English corpora. I looked at three BYU English corpora to get a picture of its rate of usage in contemporary English, its rate of usage across time, and its rate of usage by Englishes around the world.

First, I consulted the Corpus of Contemporary American English (COCA; Davies 2008). COCA has 440 million words from 1990-2012, from both spoken and written language. I conducted a simple search for four coordinators: and, but, or, and/or. For the simple coordinators and and or I ensured that a whitespace was found on either side, to prevent false positives from and/or. The results are shown in Figure 1. 


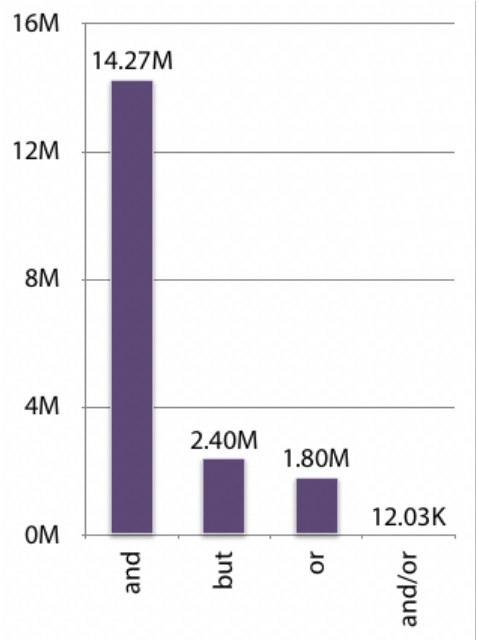

Figure 1: Token frequency of coordinators in COCA. ${ }^{9}$

And is far and away the most common coordinator, with over 14 million occurrences in COCA, followed by but with 2.4 million, and or with 1.8 million. And/or has just about 12 thousand occurrences in COCA. It is farly rare compared to the other coordinators, but nevertheless has thousands of diverse attestations in the corpus.

Next, I looked at the usage of and/or over time. I consulted the Corpus of Historical American English (COHA; Davies 2010), and again performed a search for and/or. COHA has 385 million words from 1810-2009 and provides the number of instances for a given decade. The results are shown in Figure 2.

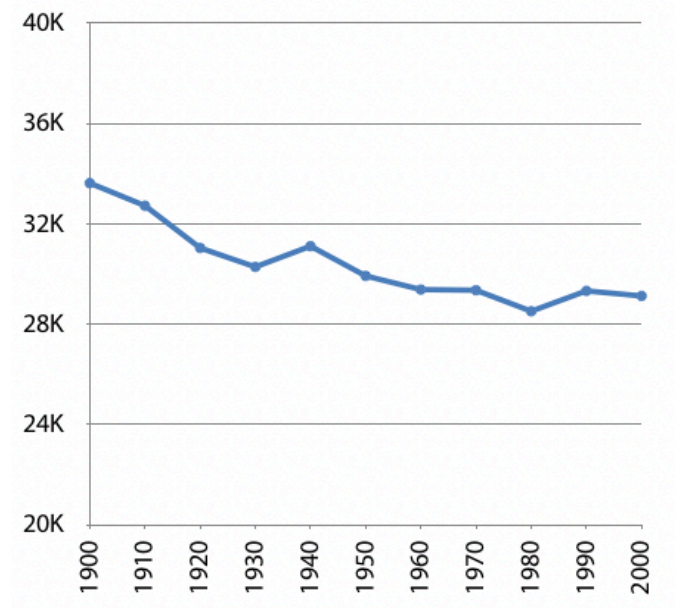

Figure 2: Token frequency per million, of and/or over time, in $\mathrm{COHA}^{10}$

The downward trend suggests that usage of and/or is decreasing, but this may only be apparent. I attribute this to shift in genres represented in the corpus over time. Although and/or is attested in all domains in contemporary English, it still retains a slightly formal flavor. It is possible there are more 'formal' texts in earlier decades, explaining the apparent higher rates of usage.

\footnotetext{
${ }^{9}$ COCA search conducted in November 2016.

${ }^{10}$ COHA search conducted in November 2016.
} 
Lastly, I looked at the use of and/or by country. I consulted the Corpus of Global WebBased English (GloWbE; Davies 2013), which has 1.8 billion words from 20 English-speaking countries. $60 \%$ of the texts are from blogs. The results are shown in Figure 3.

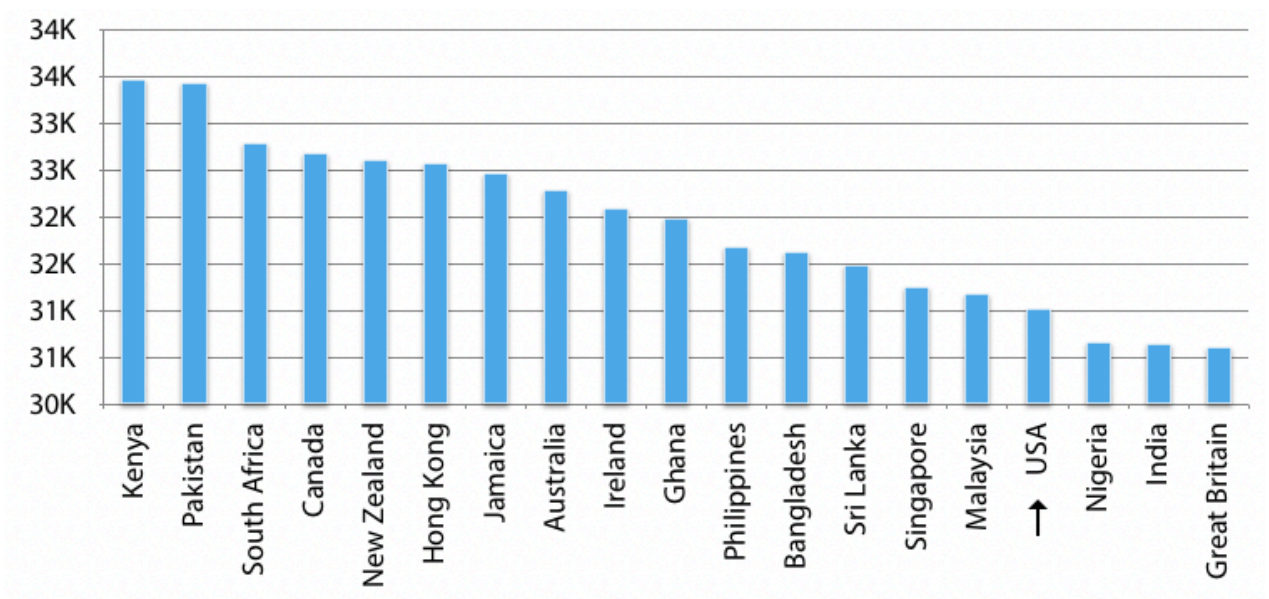

Figure 3: Token frequency of and/or across World Englishes, in GloWbE. USA is highlighted by an arrow simply for comparison. Countries on the horizonntal axis have English as official language in some capacity. ${ }^{11}$

Countries show roughly the same rate of usage, in the low 30 thousands. It is interesting to note that countries like the United States, Nigeria, Great Britain, and India tend not to use it as much as countries like Kenya, Pakistan, South Africa, and Canada.

4. Syntactic behavior. Any syntactic context where one of and or or is ungrammatical, and/or is ungrammatical. Put another way, and/or is only allowed where both and and or are. And and or have conflicting requirements when it comes to collective predicates, relational modifiers with an internal reading, anaphors, 'respectively', semantic contradiction, quantifiers, and gapping with negation. I discuss each of these in turn.

Collective predicates are those like intransitive met which require a plural subject (Winter 2001:46). The subject could denote a plural because it is a group noun like committee, as in The committee met, or the subject could denote a plural because it is a conjunction of two nouns, like The linguist and the hermit met. The coordinator in this case must be and in order to semantically combine to form a group and license the predicate, as in (7a). If it is or, the predicate is not licensed (7b). If it is and/or, the predicate is not licensed (7c).
a. $\quad$ Kyle and Pat met at the park.
b. $\quad *$ Kyle or Pat met at the park.
c. $\quad *$ Kyle and/or Pat met at the park.

Relational modifiers are those like same and different. As a predicate, these can be interpreted as having an EXTERNAL reading or an INTERNAL reading (Heim 1985). The external reading establishes a relationship between some previously-mentioned discourse referent. The

\footnotetext{
${ }^{11}$ GloWbE search conducted in November 2016.
} 
sentence John sang the same song has only an external reading: he must be singing the same song as someone previously mentioned. In sentences with plural subjects, these modifiers are ambiguous between the two readings. In the sentence John and Mary sang the same song, the external reading is the one where John and Mary are singing the same song as someone else, and the internal reading is the one where John and Mary are singing the same song as each other. For these types of sentences with a coordinated subject: if the coordinator is and, the relational modifier is ambiguous, as in (8a). If the coordinator is or (8b) or and/or (8c), the relational modifier has only the external reading.
a. Randy and Sandy sang the same song.
[Internal or External reading]
b. Randy or Sandy sang the same song.
[External reading only]
c. Randy and/or Sandy sang the same song.
[External reading only]

Anaphors exact similar requirements on their antecedents. If the anaphor is plural themselves or reciprocal each other, the antecedent must also denote a plurality (Lebeaux 1983). Like collective predicates, there are multiple strategies for forming the appropriate plurality: the antecedent can be a plural noun like students in The students congratulated themselves, or the antecedent could be a conjoined noun like John and Mary in John and Mary like each other. In the conjoined antecedent, the coordinator must be and (9a), and not or (9b) nor and/or (9c).
a. Alex and Kris saw each other.
b. $\quad *$ Alex or Kris saw each other.
c. * Alex and/or Kris saw each other.

Coordinated expressions followed by the adverb respectively (called INTERWOVEN DEPENDENCY CONSTRUCTIONS, or IDCs in Zhang (2010:169)) also require the coordinator and. In a well-formed IDC like (10a), the adverb respectively forces the coordinated predicate to distribute: Kim sang, and Sandy danced. There is no equivalent for other coordinators or (10b) and and/or (10c). ${ }^{12}$

(10) a. Kim and Sandy sang and danced, respectively.

b. $\quad$ \# Kim or Sandy sang and danced, respectively.

c. $\quad$ \# Kim and/oror Sandy sang and danced, respectively.

There are few environments where or is acceptable while and is not, but we can construct predicates with coordinated complementary antonyms to create a potential contradiction if the wrong coordinator is used. And gives rise to a contradiction (11a), while or does not (11b). And/or in this case also seems contradictory (11c).
a. \# John is alive and dead.
b. John is alive or dead.
c. \# John is alive and/or dead.

\footnotetext{
${ }^{12}$ See Eggert (2000) for discussion of potential counterexamples, like Grant or Gertrude might have drunk beer or wine, respectively (104). Eggert would however agree that 'clearly disjunctive' cases like (8b) are out.
} 
And and or behave differently when in the scope of quantifiers (Champollion 2016). Plural nouns conjoined with and are ambiguous between DISTRIBUTIVE and NON-DISTRIBUTIVE readings. Plural nouns connected with or are not; they have only the non-distributive reading. Similar to or, and/or is not ambiguous; it has only the non-distributive reading. As an example, imagine reading these instructions for a task on gathering animals for a team. The total number of expected animals depends on the coordinator. With and, it is possible to interpret (12a) as asking for 20 animals (distributive reading; 10 dogs and 10 cats) or just 10 animals (nondistributive; 10 animals, could be any mix of dogs or cats). With or, it is only possible to interpret (12b) as asking for 10 animals. Same with and/or (12c).

(12) Instructions: We are forming a team. Please select...
a. Ten dogs and cats. [Distributive: 20 animals, Non-distributive: 10 animals]
b. Ten dogs or cats. [Distributive: 20 animals, Non-distributive: 10 animals]
c. Ten dogs and/or cats. [Đistributive: 20 animals, Non-distributive: 10 animals]

Lastly, I discuss gapping with negation. And/or permits gapping, like other coordinators.

(13) a. Tom drank a beer and Mary a martini.

b. Tom drank a beer or Mary a martini.

c. Tom drank a beer and/or Mary a martini.

And and or behave differently when the scopal operator, auxiliary, and main verb are gapped. (Repp 2009). In these cases, conjunction with and is ambiguous between wide and distributive readings, paraphrased in (14). Disjunction with or is not ambiguous. It has only the wide reading (15).

(14) Ward can't eat caviar and Anna beans. (Siegel 1987:53)

Wide. It's not possible for Ward to eat caviar and Anna eat beans. $\neg(\mathrm{eWC} \& \mathrm{eAB})$

Dist. Ward can't eat caviar and Anna can't eat beans. $\neg \mathrm{eWC} \& \neg \mathrm{AB}$

(15) Ward can't eat caviar or Anna beans. (Oirsouw 1987:208)

Wide. It's not possible for Ward to eat caviar or Anna eat beans. $\neg(\mathrm{eWC}$ eAB $)$ $\neg$ eWC \& $\neg$ AB) [DeMorgans]

Dist. *Ward can't eat caviar or Anna can't eat beans. $* \neg \mathrm{eWC} \neg \mathrm{eAB}$

And/or has a complex reading.

(16) Ward cant eat caviar and/or Anna beans. Readings:

a. Either Ward can't eat caviar or Anna can't eat caviar (but I cant remember which). 


\section{b. Both of them can't eat caviar. ${ }^{13}$}

These 7 environments demonstrate the basic pattern of behavior for and/or: the set of constraints on and/or is the union of the set of constraints on and, and the set of constraints on or.

5. Appendix. In the Appendix I provide several additional naturally-occurring examples that I observed from a variety of spoken and written sources.

(17) I sometimes read books that are not that great and/or boring and/or difficult to enjoy, simply because I want to be able to have an opinion about certain books.

(18) Headedness and/or Grammatical Anarchy ${ }^{14}$

(19) This is a diamond if you love appreciate book covers (who doesn't?) or/and are a designer. ${ }^{15}$

(20) If you are applying for both a passport book and/or card, you may receive three separate mailings: one with your returned citizenship evidence; one with your newly issued passport book, and one with your newly printed passport card. ${ }^{16}$

(21) Heaven forbid a game developer, when wanting to make a level/map, takes influence from real life and/or history.

(22) What could we predict about the difficulty and/or speed of pronouncing regular words, irregular words, and pseudo words?

(23) The passive serves to topicalize an argument that is not normally a subject and/or to deemphasize the argument that normally IS the subject. ${ }^{17}$

(24) It is standard to find that object extraction is more liberal than subject and/or adjunct extraction $^{18}$

(25) If the importance of beginning and/or end letters can be fully explained by perceptual salience.

(26) Bibliography for Haj Ross and/or John Robert Ross

(27) A CHD means a child is born with an abnormally structured heart and/or large vessels.

(28) What are some dubious and/or controversial biographies you have read?

(29) My family doesnt observe Lobsterfest. I should be excused from class and/or given an A.

(30) Pancakes and/or waffles speak louder than words father.

\section{References}

Champollion, Lucas. 2016. Ten men and women got married today. Journal of Semantics 33(3). 561-622. http://dx.doi.org/10.1093/jos/ffv008.

\footnotetext{
13 This potentially corresponds to the wide scope reading, but I have not developed a formal denotation for and/or to demonstrate it.

${ }^{14}$ Conference title: http://linguistlist.org/callconf/browse- conf-action.cfm?ConfID=272296

15 Posted by a non-native English speaker from Lithuania:

https://www.goodreads.com/review/show/1265423403?booksh

${ }^{16}$ USA Application for passport or passport card Form DS-82:

https://travel.state.gov/content/passports/en/passports/information/card.html

17 Goldberg 2013:221, in Sprouse \& Hornstein 2013

18 Phillips 2013:49, in Sprouse \& Hornstein 2013
} 
Heim, Irene. 1985. Notes on comparatives and related matters. Unpublished Ms. University of Texas, Austin.

Hulsey, Sarah. 2008. Focus-sensitive coordination. MIT PhD thesis.

Munn, Alan Boag. 1993. Topics in the syntax and semantics of coordinate structures. University of Maryland $\mathrm{PhD}$ thesis.

Repp, Sophie. 2009. Negation in gapping. Oxford.

Siegel, MEA. 1984. Gapping and interpretation. Linguistic Inquiry 15. 523-30.

van Oirsouw, R. 1987. The syntax of coordination. London: Croom Helm.

Winter, Yoad. 2001. Flexibility principles in boolean semantics: the interpretation of coordination, plurality, and scope in natural language. MIT.

Woo, Brent. to appear. Effable slash: an intersective coordinator and its behavior slash properties. to appear in Proceedings of LCUGA 3.

Zhang, Niina Ning. 2010. Coordination in syntax (Cambridge Studies in Linguistics 123). Cambridge.

Zoerner, Cyril Edward. 1995. Coordination: The Syntax of \&P. University of California, Irvine. $\mathrm{PhD}$ thesis.

\section{Corpus references.}

Davies, Mark. 2008. The Corpus of Contemporary American English (COCA): 520 million words, 1990-present. Available online at http://corpus.byu.edu/coca/

Davies, Mark. 2010. The Corpus of Historical American English (COHA): 400 million words, 1810-2009. Available online at http://corpus.byu.edu/coha/

Davies, Mark. 2013. Corpus of Global Web-Based English: 1.9 billion words from speakers in 20 countries (GloWbE). Available online at http://corpus.byu.edu/glowbe/. 